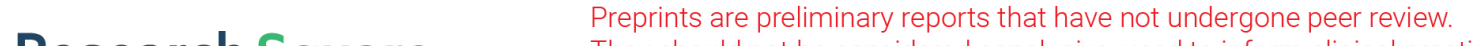 They should not be considered conclusive, used to inform clinical practice, or referenced by the media as validated information. \\ Operative Choice for Open Tibial Shaft Fracture in Children: A Comparative Study of External Fixator Vs. Elastic Stable Intramedullary Nail
}

\section{Pan Hong}

Wuhan Union Hospital https://orcid.org/0000-0003-2674-3016

\section{Saroj Rai}

Department of Orthopaedics and Trauma Surgery, National Academy of Medical Science, Mahankal,

Kathmandu,Nepal

\section{Xin Tang}

Wuhan Union Hospital

\section{Ruikang Liu}

Huazhong University of Science and Technology Tongji Medical College First Clinical College

Jin Li ( $\sim$ lijin2003whxh@foxmail.com )

Wuhan Union Hospital https://orcid.org/0000-0003-0610-2991

\section{Research Article}

Keywords: external fixator, open tibial fracture, elastic stable intramedullary nail

Posted Date: June 18th, 2021

DOl: https://doi.org/10.21203/rs.3.rs-628593/v1

License: (c) (i) This work is licensed under a Creative Commons Attribution 4.0 International License. Read Full License 


\section{Abstract}

Introduction

External fixator (EF) is a preferred choice for open tibial fractures, but pin tract infection (PTI) and refracture are common complications. Elastic stable intramedullary nail (ESIN) has been reported in the treatment for open tibial fractures. This study aims to compare the clinical outcomes of EF vs. ESIN in the treatment for open tibial shaft fracture in children retrospectively.

Material and methods

Patients aged 5-11 years old with Gustilo-Anderson II and IIIA tibial shaft fracture treated at our institute from January 2008 to January 2018 were reviewed retrospectively and categorized into EF $(n=55)$ and ESIN $(n=37)$ group. Patients with pathological fracture, neuromuscular disorder, metabolic disease, previous tibial fracture or instrumentation, and polytrauma were excluded. Patients with follow up less than 24 months or incomplete medical records were also excluded.

Results

In all, fifty-five patients (33 males, 22 females) were included in the EF group, whereas 37 patients (21 males, 16 females) were included in the ESIN group. There was no significant difference between the two groups concerning sex, age, body weight, duration from injury to surgery, Gustilo-Anderson (GA) classification, and concomitant injuries. There was no patient of nonunion and malunion in either group. The incidence of implant prominence was higher in the ESIN group (16\%) than those in the EF group (0), $\mathrm{P}<0.001$. The angulation was higher in the EF group than ESIN group in coronal and sagittal plane, $\mathrm{P}<$ 0.001 . The radiological union was faster in the ESIN group $(7.0 \pm 0.9$, weeks) than those in the EF group $(9.0 \pm 2.2), P<0.001$. Limb length discrepancy (LLD) was significantly longer in the EF group $(12.1 \pm 4.4$, $\mathrm{mm})$ than those in the ESIN group $(7.3 \pm 4.3, \mathrm{~mm}), \mathrm{P}<0.001$.

\section{Conclusion}

ESIN is a viable option in selected patients of GA grade II and IIIA open tibial fractures with comparable clinical outcomes as external fixator, but with less complications including superficial infection, residual angulation and refracture after hardware removal.

\section{Introduction}

Tibial fracture is a common injury in children, and it usually involves the diaphysis and distal metaphyseal region[1]. Closed reduction followed by a well-molded casting remains the primary choice for closed tibial shaft fracture[2,3]. However, in situations like comminuted or unstable fractures, open fractures and polytrauma, surgical stabilization is usually warranted[4-6]. Although debridement followed by casting has been reported[7], external fixator (EF) is a preferred choice for open injuries. However, pin tract infection (PTI) and refracture are common complications during the application of EF[8,9]. Besides, 
elastic stable intramedullary nail (ESIN) has been reported in the treatment for open tibial fractures $[10,11]$.

This study aims to compare the clinical outcomes of EF vs. ESIN in the treatment for open tibial shaft fracture in children retrospectively.

\section{Methods}

Patients aged 5-11 years old with open tibial shaft fracture treated at our institute from January 2008 to January 2018 were reviewed retrospectively and categorized into EF $(n=55)$ and $\operatorname{ESIN}(n=37)$ group. Gustilo-Anderson (GA) classification was adopted to stratify the patients with open injuries[12]. Patients with GA grade I injuries were excluded from this study. Patients with comminuted fracture, pathological fracture, neuromuscular disorder, metabolic disease, previous tibial fracture or instrumentation, and polytrauma were excluded. Patients with follow up less than 24 months or incomplete medical records were also excluded. Patients with body weight over $50 \mathrm{Kg}$ were excluded because ESIN was not adopted for these patients in our hospital.

Full-length anteroposterior (AP) radiograph was used to determine the total length of the tibia. Limb length discrepancy (LLD) was defined as a difference at least $2 \mathrm{~cm}$ between limbs. Angulation was measured as angle between the anatomic axes of the proximal and distal fragments, and angular deformity was defined as coronal angulation $>5$ degrees or sagittal angulation $>10$ degrees. Radiographic union was defined as the bridging callus across the fracture site on at least three out of four cortices on AP and lateral radiograph.

Complications were categorized into major and minor ones. Major complications included nonunion or loss of reduction, which required revision before fracture union. Minor complications included minor LLD or angular deformity, implant prominence, and superficial infection.

Short leg slab was used to immobilize the operated leg for 3-4 weeks postoperatively. Follow-up was scheduled at postoperative 4th, 8th, 12th week, 6th, 9th, 12th month and annually after first year.

This study was approved by the Ethics Committee of Tongji Medical College, Huazhong University of Science and Technology on November 20,2019. Written consent was obtained from the patient's legal guardians.

SPSS statistical package program (SPSS 19.0 version; SPSS Inc., Chicago, Illinois, USA) was used for statistical analysis. The categorical data were analyzed using the Chi-square $(X 2)$ test, and the continuous data were analyzed using Student's t-test. Fisher exact test was used under those circumstances with fewer subjects in groups of interest. Data were presented as mean \pm SD (range), median (range), or $\mathrm{n}(\%) . \mathrm{P}<0.05$ was considered significantly different.

\section{Results}


As shown in Table 1, fifty-five patients including 33 males and 22 females were included in the EF group, whereas 37 patients including 21 males and 16 females were included in the ESIN group, $P=0.453$. The average age of patients in the EF group was $9.0 \pm 2.8$ year-old, and that of ESIN was $9.1 \pm 2.9$ year-old, $P$ $=0.659$. Patients in both groups were followed-up for at least 2 years, with an average of 2.4 years (2-3 years). There was no significant difference between the two groups concerning sex, age, body weight, duration from injury to surgery, GA classification, and concomitant injuries.

As shown in Table 2, there was no patient of nonunion and malunion in either group. Three patients in the EF group suffered refracture after the hardware removal, but there was no case of refracture in the ESIN group. The incidence of implant prominence was higher in the ESIN group (16\%) than those in the EF group (0), $P<0.001$. The angulation was higher in the EF group than ESIN group in coronal and sagittal plane, $P<0.001$. Besides, the angulation in coronal plane was less than 5 degrees and in sagittal plane was less than 10 degrees in both groups. The incidence of superficial infection was significantly higher in the EF group (36.3\%) than those in ESIN (5.4\%) group, $\mathrm{P}<0.001$. The radiological union was faster in the ESIN group $(7.0 \pm 0.9$, weeks) than those in the EF group $(9.0 \pm 2.2), P<0.001$. Limb length discrepancy (LLD) was significantly longer in the EF group $(12.1 \pm 4.4, \mathrm{~mm})$ than those in the ESIN group $(7.3 \pm 4.3$, $\mathrm{mm}), \mathrm{P}<0.001$.

\section{Discussion}

ESIN proved to be a viable option in selected patients of open tibial shaft fractures with satisfactory clinical outcomes, but less complications than EF, including superficial infection, residual angulation and refracture after hardware removal.

Tibial shaft fractures in children usually are not complicated and treated with closed reduction and casting[13,14]. However, in patients with open fractures, and compartment syndrome, surgical intervention is usually recommended[14]. Still certain authors recommended manipulation followed by casting for open tibial fractures in children without the necessity of vascular reconstruction[15]. However, the malunion rate was not meticulously measured and analyzed[7,15]. Besides, the surgical stabilization for earlier mobilization and better alignment was gaining popularity recently[16].Therefore, for GA II and IIIA tibial shaft fracture, surgical stabilization was adopted in our hospital.

EF has been reported as a simple and effective choice for open tibial fracture[17].There were many available construct designs including circular fixator[18], monolateral fixator and hybrid external fixator[19], hexapod[20] and externalized locking plate[21]. Hybrid external fixator is easily assembled and applied with Schanz pins of different size, and it is the preferred choice in our hospital. Usually, 4 pins were sufficient for patients with simple tibial fracture. However, pin tract infection (PTI), nonunion, loss of reduction and refracture are known complications according to the literature[22]. Therefore, other instrument modality was explored.

ESIN has been reported in the treatment for open tibial fractures in children, but there were also complications including infection, delayed union and angulation $[10,11,23]$. Besides, in Gustilo-Anderson 
Type III B and C injuries, only external fixator is applied in our hospital, consistent with a previous study[24]. In patient with limited contamination such as GA grade I and II, minimal invasive technique of locking plate has also been reported[25,26]. However, the removal of plate might be troublesome. Therefore, in patients of GA grade I injury, casting followed debridement was preferred in our hospital if the fracture is stable. And ESIN was preferred if the fracture is unstable. EF was only reserved for GA grade II and III injuries. Therefore, ESIN was adopted in our hospital for selected open injuries including GA grade I, II and IIIA, after aggressive debridement.

In our study, there was no case of serious deep infection requiring secondary surgery in either group, possibly due to aggressive debridement and timely administration of antibiotics. The incidence of implant prominence was higher in the ESIN group, possibly caused by the painful bursitis around entry point[27]. Although the angulation was higher in the EF group, but the angulation in both group was within acceptable range, consistent with previous reports[28]. Superficial infections were mostly around the pin tract in the EF group, and it was managed successfully with oral antibiotics. The radiological union was faster in the ESIN group, possibly caused by the micro-motion and its stimulus to bone formation[29].

LLD is a common complication in pediatric long bone fracture[30], and the LLD was more serious in the EF group than the ESIN group, consistent with previous report[27,28]. It is a powerful testament of the superiority of ESIN.

There were 3 cases of refracture at Schanz pin site in the EF group 4-6 weeks after hardware removal because of accidental fall, and they were all managed by conservative methods. Moreover, there was no case of refracture in ESIN group. It is possibly caused by the instrumentation nature of intramedullary versus extramedullary.

We undertook a retrospective investigation; therefore, our findings should be interpreted with caution. The follow-up was not long enough, and the long-term impact upon growth remains unclear. Besides, the presence of fibular fracture was not clearly discussed in subgroup analysis. Furthermore, costeffectiveness remains to be investigated.

\section{Conclusion}

ESIN is a viable option in selected patients of GA grade II and IIIA open tibial fractures with comparable clinical outcomes as external fixator, but with less complications including superficial infection, residual angulation and refracture after hardware removal.

\section{Abbreviations}


ESIN = elastic stable intramedullary nail; EF = External fixation; $L L D=$ limb length discrepancy; GA = Gustilo-Anderson; PTI = pin tract infection; $\mathrm{AP}=$ anteroposterior

\section{Declarations}

\section{Ethics Approval}

Approval was given by the Ethics Committee of Tongji Medical College, Huazhong University of Science and Technology (IORG No. IORG0003571) on November 20, 2019.

\section{Consent to Participate}

Written consents to participate in this study were obtained from the legal guardians of every patient.

\section{Consent for publication}

Written consents were obtained from the legal guardians of every patient in this study for publication of this paper.

\section{Availability of data and materials}

Not applicable

\section{Competing interests}

The authors declare that they have no competing interests

\section{Funding}

None

\section{Author's contributions}

$\mathrm{JL}^{*}$ is in charge of the main idea and is the guarantor of integrity of the entire clinical study; PH and XT are in charge of the study concepts, design, manuscript preparation and editing; $\mathrm{PH}$ and SR are in charge of the language polishing and the grammar revision; RL and XT is in charge of the collection of the study data. All authors read and approved the final manuscript.

\section{Acknowledgement}

None

\section{References}


1. Wang H, Liu H, Wu J, Li C, Zhou Y, Liu J, et al. Age, gender, and etiology differences of sports-related fractures in children and adolescents: A retrospective observational study. Medicine (Baltimore). 2019; 98(4):e13961. doi:10.1097/MD.0000000000013961. PMID: 30681556. PMCID: PMC6358360.

2. Palmu SA, Auro S, Lohman M, Paukku RT, Peltonen JI, Nietosvaara Y. Tibial fractures in children. A retrospective 27-year follow-up study. Acta Orthop. 2014;85(5):513-7. doi: 10.3109/17453674.2014.916489. PMID: 24786903. PMCID: PMC4164870

3. Gordon JE, O'Donnell JC. Tibia fractures: what should be fixed? J Pediatr Orthop. 2012;32(1):52-61. doi: 10.1097/BPO.0b013e318254c7be PMID: 22588105

4. Liu $H$, Wang $H$, Shao B, Lu H, Zhang S, Ou L, et al. Epidemiological evaluation of traumatic lower limb fractures in children: Variation with age, gender, time, and etiology. Medicine (Baltimore). 2019;98(38):e17123. doi: 10.1097/MD.0000000000017123. PMID: 31567950. PMCID: PMC6756687.

5. Stenroos A, Jalkanen J, Sinikumpu JJ, Palmu S, Koskimies-Virta E, Laaksonen T, et al. Treatment of unstable pediatric tibia shaft fractures in Finland. Eur J Pediatr Surg. 2019; 29(3):247-52. doi: 10.1055/s-0038-1632373. PMID: 29490379

6. Canavese F, Botnari A, Andreacchio A, Marengo L, Samba A,Dimeglio A, et al. Displaced tibial shaft fractures with intact fibula in children: nonoperative management versus operative treatment with elastic stable intramedullary nailing. J Pediatr Orthop. 2016;36(7):667-72. doi:

10.1097/BPO.0000000000000528. PMID: 26151246

7. Charalambous $C P$, Alvi F, Siddique I, Zenios M, Hirst P, Marshall P. Casting versus surgical fixation for grade IIIA open tibial diaphysial fractures in children: effect on the rate of infection and the need for secondary surgical procedures to promote bone union. Int Orthop. 2005;29(6):392-5. doi: 10.1007/s00264-005-0009-3. PMID: 16091949. PMCID: PMC2231577

8. Norman D, Peskin B, Ehrenraich A, Rosenberg N, Bar-Joseph G, Bialik V. The use of external fixators in the immobilization of pediatric fractures. Arch Orthop Trauma Surg. 2002;122:379-82 doi: 10.1007/s00402-001-0383-2. PMID: 12228797

9. Dai J, Wang X, Zhang F, Zhu L, Zhen Y. Treatment of distal metaphyseal tibia fractures using an external fixator in children. Medicine (Baltimore). 2019;98(36):e17068. doi: 10.1097/MD.0000000000017068. PMID: 31490405 PMCID: PMC6738966

10. Pandya NK, Edmonds EW. Immediate intramedullary flexible nailing of open pediatric tibial shaft fractures. J Pediatr Orthop. 2012;32:770-6. doi: 10.1097/BPO.0b013e318270468b. PMID: 23147618

11. Pandya NK. Flexible Intramedullary Nailing of Unstable and/or Open Tibia Shaft Fractures in the Pediatric Population. J Pediatr Orthop. 2016;36(1):19-23. doi: 10.1097/BP0.0000000000000754. PMID: 27078231

12. Papakostidis C, Kanakaris NK, Pretel J, Faour O, Morell DJ, Giannoudis PV. Prevalence of complications of open tibial shaft fractures stratified as per the Gustilo-Anderson classification. 
Injury.2011;42(12):1408-15. doi:10.1016/j.injury.2011.10.015 doi: 10.1016/j.injury.2011.10.015. PMID: 22019355

13. Cruz Al Jr, Raducha JE, Swarup I, Schachne JM, Fabricant PD. Evidence-based update on the surgical treatment of pediatric tibial shaft fractures. Curr Opin Pediatr. 2019;31(1):92-102. doi: 10.1097/MOP.0000000000000704. PMID: 30461511

14. Lardelli P, Frech-Dörfler M, Holland-Cunz S, Mayr J. Slow Recovery of Weight Bearing After Stabilization of Long-Bone Fractures Using Elastic Stable Intramedullary Nails in Children. Medicine (Baltimore). 2016;95(11):e2966. doi: 10.1097/MD.0000000000002966. PMID: 26986106 PMCID: PMC4839887

15. Jones BG, Duncan RD. Open tibial fractures in children under 13 years of age-10 years experience. Injury. 2003;34(10):776-80. doi: 10.1016/s0020-1383(03)00031-7. PMID: 14519359.

16. Stenroos A, Jalkanen J, Sinikumpu JJ, Palmu S, Koskimies-Virta E, Laaksonen T, et al. Treatment of Unstable Pediatric Tibia Shaft Fractures in Finland. Eur J Pediatr Surg. 2019;29(3):247-52. doi: 10.1055/s-0038-1632373. PMID: 29490379

17. Nandra RS, Wu F, Gaffey A, Bache CE. The management of open tibial fractures in children: a retrospective case series of eight years' experience of 61 cases at a paediatric specialist centre. Bone Joint J. 2017;99B(4):544-53. doi: 10.1302/0301-620X.99B4.37855. PMID: 28385946

18. Monsell FP, Howells NR, Lawniczak D, Jeffcote B, Mitchell SR. High-energy open tibial fractures in children: treatment with a programmable circular external fixator. J Bone Joint Surg Br. 2012;94(7):989-93. doi: 10.1302/0301-620X.94B7.28333 PMID: 22733958

19. Bisaccia M, Rinonapoli G, Di Giacinto S, Schiavone A, Lazzeri S, Gomez-Garrido D,et al. Tibial diaphyseal fractures in children: indications and limitations of the treatment with monolateral and hybrid external fixator . Med Glas (Zenica). 2020;17(2):509-16. doi: 10.17392/1159-20. PMID: 32329324

20. lobst CA. Hexapod External Fixation of Tibia Fractures in Children. J Pediatr Orthop. 2016;36(1):248. doi: 10.1097/BPO.0000000000000764. PMID: 27078228

21. Radhakrishna VN, Madhuri V. Management of pediatric open tibia fractures with supracutaneous locked plates. J Pediatr Orthop B. 2018;27(1):13-6. doi: 10.1097/BPB.0000000000000425. PMID: 28079741

22. Humphrey JA, Gillani S, Barry MJ. The role of external fixators in paediatric trauma. Acta Orthop Belg. 2015;81(3):363-7.PMID: 26435228

23. Economedes DM, Abzug JM, Paryavi E, Herman MJ. Outcomes using titanium elastic nails for open and closed pediatric tibia fractures. Orthopedics. 2014;37(7):e619-24. doi: 10.3928/0147744720140626-52.

24. Laine JC, Cherkashin A, Samchukov M, Birch JG, Rathjen KE. The Management of Soft Tissue and Bone Loss in Type IIIB and IIIC Pediatric Open Tibia Fractures. J Pediatr Orthop. 2016;36(5):4538. doi: 10.1097/BPO.0000000000000492. PMID: 25887835 
25. Kim JW, Oh CW, Jung WJ, Kim JS. Minimally invasive plate osteosynthesis for open fractures of the proximal tibia. Clin Orthop Surg. 2012;4(4):313-20. doi: 10.4055/cios.2012.4.4.313. PMID: 23205242 PMCID: PMC3504697

26. Özkul E, Gem M, Arslan H, Alemdar C, Azboy I, Arslan SG. Minimally Invasive Plate Osteosynthesis in Open Pediatric Tibial Fractures. J Pediatr Orthop. 2016;36(4):416-22. doi: 10.1097/BPO.0000000000000451.

27. Aslani H, Tabrizi A, Sadighi A, Mirbolook AR. Treatment of pediatric open femoral fractures with external fixator versus flexible intramedullary nails. Arch Bone Jt Surg. 2013;1(2):64-7. PMID: 25207290 PMCID: PMC4151412

28. Ramasubbu RA, Ramasubbu BM. Surgical stabilization for open tibial fractures in children: External fixation or elastic stable intramedullary nail - which method is optimal? Indian J Orthop. 2016;50(5):455-63. doi: 10.4103/0019-5413.189613 PMID: 27746486 PMCID: PMC5017165

29. Shen K, Cai H, Wang Z, Xu Y. Elastic stable intramedullary nailing for severely displaced distal tibial fractures in children. Medicine (Baltimore). 2016;95(39):e4980. doi:

10.1097/MD.0000000000004980.

30. Hogue GD, Wilkins KE, Kim IS. Management of Pediatric Tibial Shaft Fractures. J Am Acad Orthop Surg. 2019;27(20):769-78. doi: 10.5435/JAAOS-D-17-00819.

\section{Tables}

Table 1 Patient demographics

\begin{tabular}{|c|c|c|c|c|c|}
\hline \multicolumn{3}{|c|}{ Parameters } & $E F(N=55)$ & ESIN $(N=37)$ & $P$ value \\
\hline \multirow[t]{2}{*}{ Sex } & \multicolumn{2}{|c|}{ Male } & $33(60.0 \%)$ & $21(56.8 \%)$ & 0.453 \\
\hline & \multicolumn{2}{|c|}{ Female } & $22(40.0 \%)$ & $16(43.2 \%)$ & \\
\hline \multicolumn{3}{|c|}{ Age $(y)$} & $9.0 \pm 2.8$ & $9.1 \pm 2.9$ & 0.659 \\
\hline \multicolumn{3}{|c|}{ Body weight (kg) } & $27.9 \pm 4.8$ & $28.4 \pm 5.2$ & 0.561 \\
\hline \multirow[t]{2}{*}{ Side } & \multicolumn{2}{|c|}{ Left } & $27(49.1 \%)$ & 19 (51.4\%) & 0.856 \\
\hline & \multicolumn{2}{|c|}{ Right } & $28(50.9 \%)$ & $18(48.6 \%)$ & \\
\hline \multicolumn{3}{|c|}{ From injury to surgery (h) } & $4.1 \pm 1.5$ & $4.3 \pm 1.3$ & 0.496 \\
\hline \multirow{2}{*}{\multicolumn{2}{|c|}{$\begin{array}{l}\text { Gustilo-Anderson } \\
\text { Classification }\end{array}$}} & II & $31(56 \%)$ & $21(56.7 \%)$ & \multirow[t]{2}{*}{0.479} \\
\hline & & IIIA & 24 (44\%) & 16 (43.3) & \\
\hline \multicolumn{3}{|c|}{ Concomitant injuries } & 35 (64\%) & 27 (72\%) & 0.128 \\
\hline \multicolumn{3}{|c|}{ Presence of fibular fracture } & $20(36 \%)$ & $14(37.8 \%)$ & 0.147 \\
\hline
\end{tabular}


$\mathrm{EF}=$ hybrid external Fixator; ESIN = elastic stable intramedullary nail

Concomitant injuries: head, thoracic and abdominal, pelvic injuries

Table 2 Clinical outcomes

\begin{tabular}{|c|c|c|c|c|}
\hline \multicolumn{2}{|l|}{ Complication } & $E F(N=55)$ & ESIN $(N=37)$ & $P$ value \\
\hline \multicolumn{2}{|l|}{ Malunion } & 0 & 0 & $>0.999$ \\
\hline \multicolumn{2}{|l|}{ Non-union } & 0 & 0 & $>0.999$ \\
\hline \multicolumn{2}{|l|}{ Refracture } & $3(5 \%)$ & 0 & 0.100 \\
\hline \multicolumn{2}{|l|}{ Implant prominence } & 0 & $6(16 \%)$ & $<0.001$ \\
\hline \multirow[t]{2}{*}{ Angulation(Degree) } & Coronal & $3.4 \pm 1.4$ & $1.9 \pm 1.2$ & $0.017 *$ \\
\hline & Sagittal & $5.7 \pm 3.1$ & $4.6 \pm 3.1$ & $0.043^{\star}$ \\
\hline \multicolumn{2}{|l|}{ Superficial infection } & $20(36.3 \%)$ & $2(5.4 \%)$ & $<0.001 *$ \\
\hline \multicolumn{2}{|l|}{ Hardware removal (w) } & $12.7 \pm 3.6$ & $24.9 \pm 4.8$ & $<0.001^{*}$ \\
\hline \multicolumn{2}{|l|}{ Radiological union (w) } & $9.0 \pm 2.2$ & $7.0 \pm 0.9$ & $0.025^{\star}$ \\
\hline \multicolumn{2}{|c|}{$\operatorname{LLD}(\mathrm{mm})$ at last follow-up } & $12.1 \pm 4.4$ & $7.3 \pm 4.3$ & $<0.001 *$ \\
\hline
\end{tabular}

Major complications: loss of reduction, non-union, refracture

Minor complications: implant prominence, mild angulation, superficial infection

LLD = limb length discrepancy

$*<0.05$

Figures 

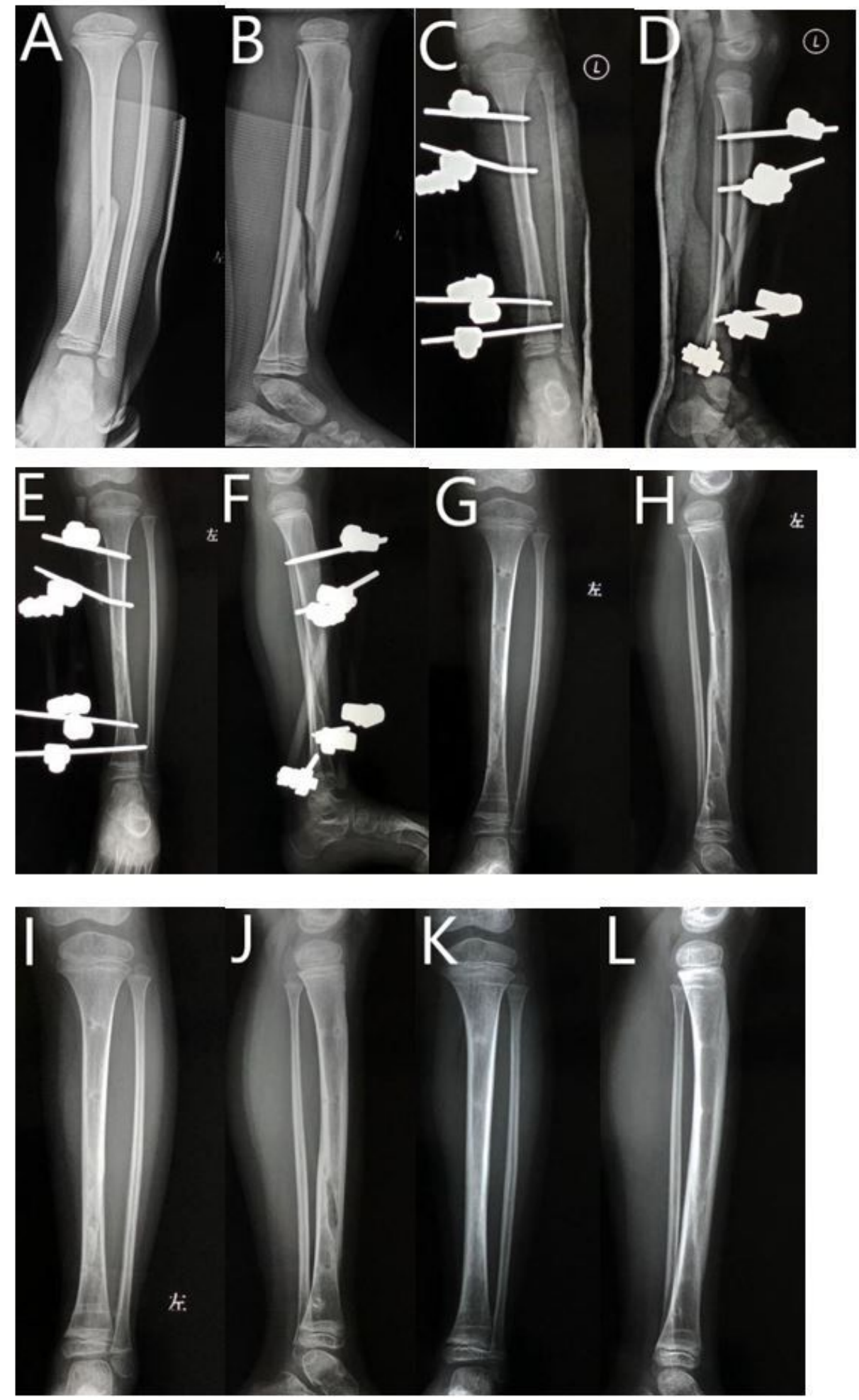

\section{Figure 1}

Six year-old boy with Gustilo-Anderson grade II tibial fracture treated with EF A. AP view of tibia before surgery B. Lateral view of tibia before surgery C. AP view of tibia after surgery D. Lateral view of tibia after surgery E. AP view of tibia at 8th week follow-up F. Lateral view of tibial at 8th week follow-up G. AP view of tibia after hardware removal at 11th week follow-up $\mathrm{H}$. Lateral view of tibia after hardware removal at 
11th week follow-up I. AP view of tibia at 5th month follow-up J. Lateral view of tibia at 5th month followup K. AP view of tibia at 12 th month follow-up L. Lateral view of tibia at 12th month follow-up
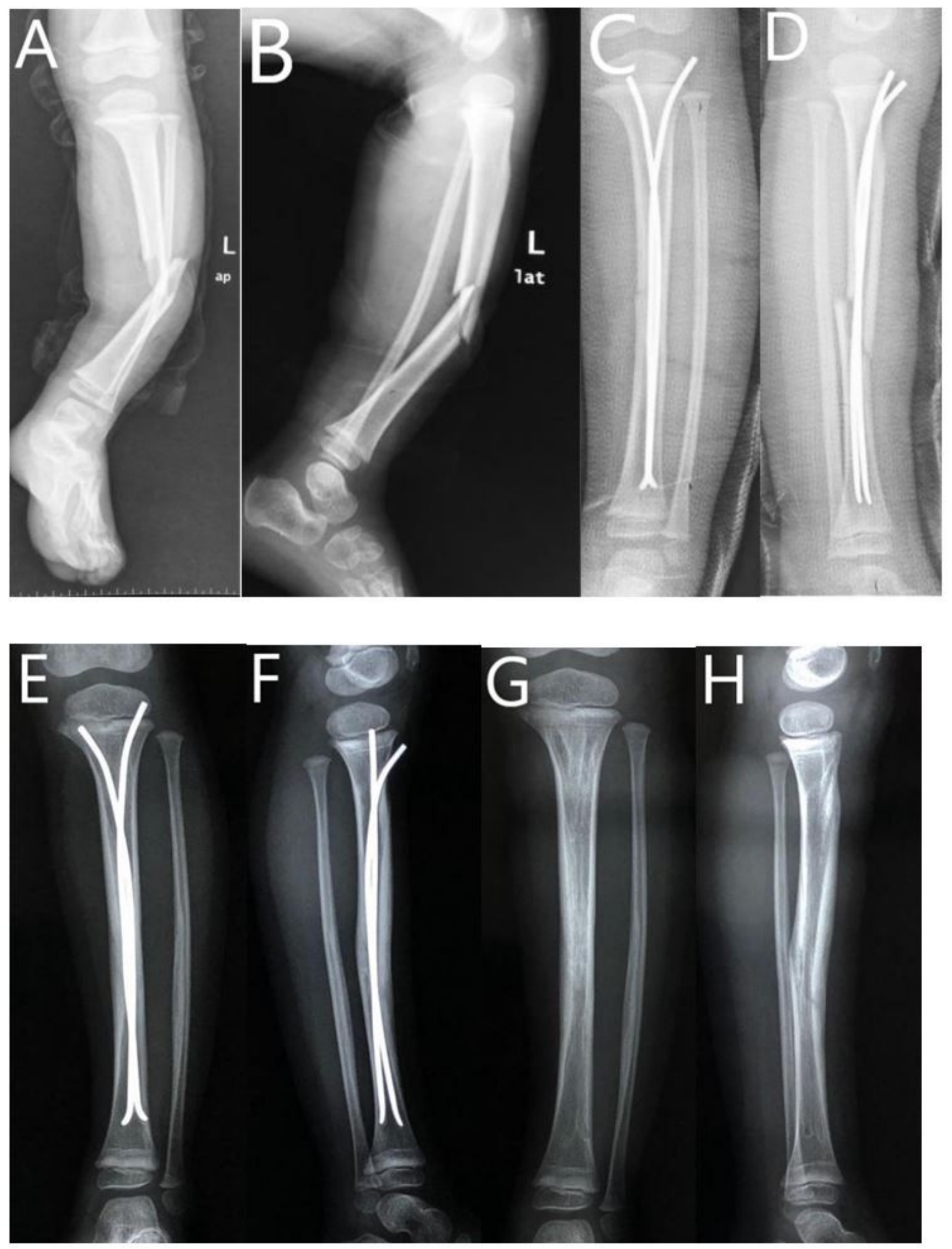

Figure 2

Five year-old girl with Gustilo-Anderson grade IIIA tibial fracture treated with ESIN A. AP view of tibia before surgery B. Lateral view of tibia before surgery C. AP view of tibia after surgery D. Lateral view of 
tibia after surgery E. AP view of tibia at 5th month follow-up F. Lateral view of tibia at 5th month followup G. AP view of tibia after hardware removal $\mathrm{H}$. Lateral view of tibia after hardware removal 